\title{
Analysis of Stochastic Model on a Two-Unit Hot Standby Combined Hardware-Software System
}

\author{
Rajeev Kumar \\ Department of Mathematics, \\ M.D. University, Rohtak-124001, INDIA
}

\author{
Sudesh Kumari \\ Department of Mathematics, \\ M.D. University, Rohtak-124001, INDIA
}

\begin{abstract}
This paper deals with a stochastic model for a two-unit hot standby combined hardware-software system in which one unit is operative and the other is hot standby. The operative unit may have hardware or software failures and goes to repair. This leads to degradation of the system and then hot standby unit is under operation. Further on hardware or software failures of the hot standby unit the system goes to complete failures. Various measures of performance of the system are obtained using semiMarkov process and regenerative point techniques. Numerical results and graphs pertaining to a particular case are also included.
\end{abstract}

\section{General Terms}

Stochastic Process

\section{Keywords}

Two-Unit Hot Standby System, Combined hardwaresoftware system, reliability, mean up time, profit, semiMarkov and Regenerative point techniques.

\section{INTRODUCTION}

In the recent years, a large number of hardware-software systems have been developed and adopted due to their practical applications and common man's affordability and inherent reliability. A hardware-software system consists of hardware and software subsystems. Most of the modern systems like mobiles, computers, robots, missiles, rockets, electronic meters, washing machines etc. are improvement over hardware-software systems. Today society and its Institutions are becoming more and more depend on many such systems. A few of the numerous applications of the hardware and software systems are control of communications and transport systems, automated plants operations and even in routine activities e.g. reservation of tickets, computation of various bills and in business. All these things demands high reliability since failure of any can be costly and hazardous. At present it is a matter of great importance to produce and provide the cost-effective, efficient, user friendly hardware-software system having higher reliability.

For effective performance of the hardware-software system, both its hardware and software components must function with considerable reliability. As the hardwaresoftware systems are more complex and the demand on their reliability has increased exponentially. For the reliability analysis of the one-unit hardware-software system, combined reliability model i.e. considering both hardware and software components were discussed by some researchers such as Boyd and Monahan [1],

Friedman and Tran [2], Hecht and Hecht [3], Huang et al.[4], Iyer and Velardi [5], Kanoun and Ortalo-Borrel [6], Kumar and Malik [7], Kumar and Kumar [8], Martin and
Mathur [9], Teng et al. [10], Trivedi [11], Trivedi et al. [12], Welke et al. [13] etc. However, analysis of a twounit hot standby hardware-software system with respect to its reliability, availability and profit has not been reported in the literature of reliability modeling.

Keeping this in view, in the present paper, a stochastic model for two identical units hot standby combined hardware-software system is analyzed. Initially, one unit is operative and other is hot standby and any one of the units may have a hardware or software component failure. On failure of a unit either due to hardware or software component failure, the system goes to degraded state and when both the units fails the system goes to complete failure. It is assumed here that hardware and software failures are independent of each other and occurs only due to hardware and software components, respectively. Further, it is assumed that there is single repair facility/engineer that handles all types of hardware or software failures and reaches the system in negligible time.

Other assumptions of the model are:

1. After each hardware/software repair, the system is as good as new.

2. If a unit is under repair, it does not work for the system.

3. The times to failures are exponentially distributed whereas recovery/repair time distributions are general.

4. All random variables are mutually independent.

5. Switching is perfect and instantaneous.

Various measures of system performance are obtained using semi Markov Process and regenerative point techniques. The expressions for various measures of system performance are obtained such as mean time to system failure, mean up time, expected number of software repairs, expected number of hardware repairs, expected number of visits by repairman. Expected profit incurred for the system is also computed using above measures. Various conclusions regarding reliability and profit of the system are drawn on the basis of graphical studies.

\section{NOTATIONS}

O : $\quad$ Operative unit.

$\mathrm{F}_{\mathrm{sr}} \quad$ : $\quad$ Software failure is not recovered and unit is under manual repair.

$\mathrm{F}_{\mathrm{hr}} \quad$ : Hardware failure is not recovered and unit is under manual repair.

$\mathrm{F}_{\mathrm{sR}} \quad$ : $\quad$ Software repair is continuing from the previous state. 


$\begin{array}{lll}\mathrm{F}_{\mathrm{hR}} & : & \begin{array}{l}\text { Hardware repair is continuing from the } \\ \text { previous state. }\end{array} \\ \mathrm{F}_{\mathrm{sW}} & : & \begin{array}{l}\text { Unit is under software failure and it is } \\ \text { waiting for repair. }\end{array} \\ \mathrm{F}_{\mathrm{hW}} & : & \begin{array}{l}\text { Unit is under hardware failure and it is } \\ \text { waiting for repair. }\end{array} \\ \lambda_{\mathrm{s}} & : & \text { Software failure rate. } \\ \lambda_{\mathrm{h}} & : & \text { Hardware failure rate. } \\ \alpha_{\mathrm{s}} & : & \text { Software repair rate. } \\ \alpha_{\mathrm{h}} & : & \text { Hardware repair rate. } \\ \mathrm{g}_{\mathrm{s}}(\mathrm{t}) \quad: & \text { P.d.f. of time to software repair. } \\ \mathrm{g}_{\mathrm{h}}(\mathrm{t}) \quad: \quad & \text { P.d.f. of time to hardware repair. }\end{array}$

The transition diagram depicting the various states of the system is shown in the fig.1.The epochs of entry into the states $0,1,2$ are regenerative points and thus the states 0 , 1,2 are regenerative states and 3, 4, 5, 6 are failed states.

\section{MEASURES OF THE SYSTEM PERFORMANCE}

\subsection{Transition Probabilities}

The transition probabilities $\mathrm{p}_{\mathrm{ij}}$ are given by

$$
\begin{array}{ll}
\mathrm{p}_{01}=\lambda_{\mathrm{s}} / S & \mathrm{p}_{02}=\lambda_{\mathrm{h}} / \mathrm{S} \\
\mathrm{p}_{10}=\alpha_{\mathrm{s}} / S_{1} & \mathrm{p}_{13}=\lambda_{\mathrm{s}} / S_{1} \\
\mathrm{p}_{14}=\lambda_{\mathrm{h}} / \mathrm{S}_{1} & \mathrm{p}_{20}=\alpha_{\mathrm{h}} / S_{2} \\
\mathrm{p}_{25}=\lambda_{\mathrm{s}} / \mathrm{S}_{2} & \mathrm{p}_{26}=\lambda_{\mathrm{h}} / \mathrm{S}_{2} \\
\mathrm{p}_{11}^{(3)}=\lambda_{\mathrm{s}} / \mathrm{S}_{1} & \mathrm{p}_{12}^{(4)}=\lambda_{\mathrm{h}} / \mathrm{S}_{1} \\
\mathrm{p}_{21}^{(5)}=\lambda_{\mathrm{S}} / S_{2} & \mathrm{p}_{22}^{(6)}=\lambda_{\mathrm{h}} / \mathrm{S}_{2}
\end{array}
$$

By these transition probabilities it can be verified that

$$
\begin{array}{ll}
\mathrm{p}_{01}+\mathrm{p}_{02}=1 & \mathrm{p}_{10}+\mathrm{p}_{13}+\mathrm{p}_{14}=1 \\
\mathrm{p}_{20}+\mathrm{p}_{25}+\mathrm{p}_{26}=1 & \mathrm{p}_{10}+\mathrm{p}_{11}^{(3)}+\mathrm{p}_{12}^{(4)}=1 \\
\mathrm{p}_{20}+\mathrm{p}_{21}^{(5)}+\mathrm{p}_{22}^{(6)}=1 &
\end{array}
$$

where

$$
\mathrm{S}=\lambda_{\mathrm{s}}+\lambda_{\mathrm{h}}, \quad \mathrm{S}_{1}=\lambda_{\mathrm{s}}+\lambda_{\mathrm{h}}+\alpha_{\mathrm{s}}, \quad \mathrm{S}_{2}=\lambda_{\mathrm{s}}+\lambda_{\mathrm{h}}+\alpha_{\mathrm{h}},
$$

\subsection{Mean Sojourn Time}

The mean sojourn time $\left(\mu_{\mathrm{i}}\right)$ in the $\mathrm{i}^{\text {th }}$ state is the expected first passage time taken by the unit at the $\mathrm{i}^{\text {th }}$ state before transiting to any other state.

$$
\mu_{\mathrm{i}}=\int_{0}^{\infty} \operatorname{Pr}\left(\mathrm{T}_{\mathrm{i}}>t\right) \mathrm{dt}
$$

where $T_{i}$ is the p.d.f. of device life time.

Therefore,

$$
\begin{array}{lll}
\mu_{0}=1 / 2 \mathrm{~S} & ; & \mu_{1}=1 / \mathrm{S}_{1} \\
\mu_{2}=1 / \mathrm{S}_{2} & ; & \mathrm{K}_{1}=1 / \alpha_{\mathrm{s}} ; \\
\mathrm{K}_{2}=1 / \alpha_{\mathrm{h}} & &
\end{array}
$$

\subsection{Unconditional Mean Time}

The unconditional mean time $\left(\mathrm{m}_{\mathrm{ij}}\right)$ taken by the system to transition for any regenerative state $\mathrm{j}$, when it (time) is counted from epoch of entrance into that state $i$ is, mathematically, stated as:

$$
\mathrm{m}_{\mathrm{ij}}=\int_{0}^{\infty} \mathrm{tq}_{\mathrm{ij}}(\mathrm{t}) \mathrm{dt}=-\mathrm{q}_{\mathrm{ij}}^{*^{\prime}}(0)
$$

Thus,

$$
\begin{gathered}
\mathrm{m}_{01}=\lambda_{\mathrm{s}} / 2 \mathrm{~S}^{2} ; \quad \mathrm{m}_{02}=\frac{\lambda_{\mathrm{h}}}{2 \mathrm{~S}^{2}} ; \quad \mathrm{m}_{10}=\alpha_{\mathrm{s}} / \mathrm{S}_{1}^{2} ; \\
\mathrm{m}_{13}=\lambda_{\mathrm{s}}\left[1-\alpha_{\mathrm{s}} \mathrm{S} / \mathrm{S}_{1}^{2}-\alpha_{\mathrm{s}} / \mathrm{S}_{1}^{2}\right] / \mathrm{S}^{2}
\end{gathered}
$$

\section{OTHER MEASURES OF THE SYSTEM PERFORMANCE}

By probabilistic arguments for the regenerative process, the recursive relations for various measures of the system performance are obtained. Then on solving the relations using Laplace-Stieltjes transforms, we get the following measures:

$\begin{array}{lr}\text { Mean Time to System Failure } & T_{0}=\frac{N}{D} \\ \text { Mean Up Time } & A_{0}=\frac{N_{1}}{D_{1}} \\ \text { Expected Number of Hardware Repair } & H_{R 0}=\frac{N_{3}}{D_{1}} \\ \text { Expected Number of Software Repairs } & S_{R 0}=\frac{N_{4}}{D_{1}}\end{array}$

Expected Number of Visits by the Repairman $V_{0}=$ $\frac{N_{5}}{D_{1}}$ where

$\mathrm{D}=1-\mathrm{p}_{01} \mathrm{p}_{10}-\mathrm{p}_{02} \mathrm{p}_{20}$

$\mathrm{D}_{1}=\mu_{0}\left[\mathrm{p}_{10} \mathrm{p}_{21}^{(5)}+\mathrm{p}_{20}\left(1-\mathrm{p}_{11}^{(3)}\right)\right]+\left(\mathrm{p}_{01} \mathrm{p}_{20}+\mathrm{p}_{21}^{(5)}\right) \mathrm{K}_{1}$ $+\left(1-\mathrm{p}_{01} \mathrm{p}_{10}-\mathrm{p}_{11}^{(3)}\right) \mathrm{K}_{2}$

$\mathrm{N}=\mu_{0}+\mu_{1} \mathrm{p}_{01}+\mu_{2} \mathrm{p}_{02}$

$\mathrm{N}_{1}=\mu_{0}\left[\mathrm{p}_{20}\left(1-\mathrm{p}_{11}^{(3)}\right)+\mathrm{p}_{10} \mathrm{p}_{21}^{(5)}\right]$

$\left.\mathrm{N}_{2}=\mu_{1}\left[\mathrm{p}_{01} \mathrm{p}_{20}+\mathrm{p}_{21}^{(5)}\right]+\mu_{2}\left[1-\mathrm{p}_{01} \mathrm{p}_{10}-\mathrm{p}_{11}^{(3)}\right)\right]$

$\mathrm{N}_{3}=\left[1-\mathrm{p}_{01}\right] \mathrm{p}_{10}+\mathrm{p}_{12}^{(4)}$

$\mathrm{N}_{4}=\mathrm{p}_{01} \mathrm{p}_{20}+\mathrm{p}_{21}^{(5)}$

$\mathrm{N}_{5}=\left(\mathrm{p}_{10}+\mathrm{p}_{12}^{(4)}\right) \mathrm{p}_{20}+\mathrm{p}_{10} \mathrm{p}_{21}^{(5)}$

\section{PROFIT ANALYSIS}

The expected total profit $\left(\mathrm{P}_{0}\right)$ incurred to the system in steady state is given by

$\mathrm{P}_{0}=\mathrm{C}_{0} \mathrm{~A}_{0}+\mathrm{C}_{1} \mathrm{D}_{0}-\mathrm{C}_{2} \mathrm{H}_{\mathrm{R} 0}-\mathrm{C}_{3} \mathrm{~S}_{\mathrm{R} 0}-\mathrm{C}_{4} \mathrm{~V}_{0}-\mathrm{C}_{5}$

where

$\mathrm{C}_{0}=$ revenue per unit up time of the system.

$\mathrm{C}_{1}=$ revenue per unit degradation time of the system.

$\mathrm{C}_{2}=$ cost per unit of hardware repair

$\mathrm{C}_{3}=$ cost per unit of software repair.

$\mathrm{C}_{4}=$ cost per visit of the repairman.

$\mathrm{C}_{5}=$ installation cost. 


\section{PARTICULAR CASE}

For the analysis purpose, the following particular case is taken:

$g_{s}(t)=\alpha_{s} e^{-\alpha_{s} t}$

$g_{h}(t)=\alpha_{h} e^{-\alpha_{h} t}$

The values of the various failure rates and repair rates are assumed as, i.e $\lambda_{\mathrm{h}}=.01, \lambda_{\mathrm{h}}=.001, \lambda_{\mathrm{h}}=.002, \lambda_{\mathrm{s}}=.0002$, $\lambda_{\mathrm{s}}=.002, \alpha_{\mathrm{h}}=.2, \alpha_{\mathrm{h}}=.6, \alpha_{\mathrm{h}}=.8, \alpha_{\mathrm{h}}=1.8, \alpha_{\mathrm{s}}=.3, \alpha_{\mathrm{s}}=.5, \alpha_{\mathrm{s}}=.6$, $\alpha_{\mathrm{s}}=.7, \mathrm{C}_{0}=30000, \mathrm{C}_{1}=30000, \mathrm{C}_{2}=500, \mathrm{C}_{3}=300$,

$\mathrm{C}_{4}=20, \mathrm{C}_{5}=24000$ etc

\section{GRAPHICAL ANALYSIS}

Using the above particular case and the assumed values of parameters, various graphs are plotted for mean time to system failure $\left(\mathrm{T}_{0}\right)$, mean up time $\left(\mathrm{A}_{0}\right)$, mean degradation time $\left(\mathrm{D}_{0}\right)$ and profit $\left(\mathrm{P}_{0}\right)$ of the system for different values of hardware and software failures rates $\left(\lambda_{h}, \lambda_{s}\right)$ and repair rates $\left(\alpha_{h}, \alpha_{s}\right)$, respectively.

Fig. 2 and fig. 3 depicts the behavior of mean time to system failure $\left(\mathrm{T}_{0}\right)$ with respect to various hardware and software failure rates $\left(\lambda_{\mathrm{h}}, \lambda_{\mathrm{s}}\right)$, respectively for different values of hardware and software repair rates $\left(\alpha_{\mathrm{h}}, \alpha_{\mathrm{s}}\right)$. It can be seen that mean time to system failure decreases as hardware and software failure rates increase and further mean time to system failure increases with higher values of repair rates.

Fig. 4 and fig. 5, shows the behavior of mean up time $\left(\mathrm{A}_{0}\right)$ with respect to various hardware and software failure rates $\left(\lambda_{\mathrm{h}}, \lambda_{\mathrm{s}}\right)$, respectively for different values of hardware and software repair rates $\left(\alpha_{h}, \alpha_{s}\right)$. From the graphs, it can be seen that mean up time decreases with the increase in the values of hardware and software failure rates and further mean up time increases with higher values of repair rates.

Fig. 6 and fig. 7 reveals the pattern of the profit $\left(\mathrm{P}_{0}\right)$ incurred to the system with respect to hardware and software failure rates $\left(\lambda_{h}, \lambda_{s}\right)$. It can be seen that the profit $\left(\mathrm{P}_{0}\right)$ of the system decreases as the failure rates increases whereas increases for higher values of repair rates.

\section{CONCLUSIONS}

It can be observed that reliability, mean up time and profit of the two unit hot standby hardware-software system decrease as hardware and software failure rates increases and these increases with higher values of hardware and software repair rates. The limits of hardware and software failure/repair rates can be obtained for the system to give positive profit that may be quite useful for both the system developer and the system user.

\section{REFERENCES}

[1] Boyd, M.A. and Monahan, C. M., 1995 Developing Integrated Hardware-Software System Reliability models:
Difficulties and Issues [For Digital Avionics]. Proceeding of the Digital Avionics Systems Conference, $14^{\text {th }}$ DASC, pp.193-198, Cambridge, USA.

[2] Friedman, M.A. and Tran, P., 1992. Reliability Techniques for Combined Hardware/Software Systems, Proceeding Annual Reliability and Maintainability Symposium, pp.290-293

[3] Hecht and Hecht, 1986. Software Reliability in The System Context, IEEE Transactions on Software Engineering, Vol.-12, pp.51-58.

[4] Huang, B., Li, X., Li, M., Bernstein, J. and Smidts, C.,2005. Study of the Impact of Hardware Fault on Software Reliability, Proc. $16^{\text {th }}$ IEEE Int'1 Symp. Software Reliability Engineering.

[5] Iyer, R.K. and Velardi, P., 1985. Hardware related Software Errors: Measurement and Analysis. IEEE Transactions on Software Engineering, Vol.11, pp.223230

[6] Kanoun, K. and Ortalo-Borrel, M., 2000. Fault-Tolerant System Dependency-Explicit Modeling of Hardware and Software Component-Interactions, IEEE Transactions Reliability, Vol. 49, No. 4, pp. 363-376.

[7] Kumar, A. and Malik, S.C., 2012. Stochastic Modeling of a Computer System with Priority to PM over S/W Replacement Subject to Maximum Operation and Repair, International Journal of Computer Applications, Vol.43, No.3, pp. 27-34.

[8] Kumar, R. and Kumar, M. 2012. Performance and Cost Benefit Analysis of a Hardware-Software System Considering Hardware based Software Interactions Failures and Different Types of Recovery, International Journal of Computer Applications, Vol. 53, No.-17, pp.2532

[9] Martin, R. and Mathur, A.P., 1990. Software and Hardware Quality Assurance: Towards a Common Platform for Increase the Usability of this Methodology, Proc. IEEE Conf. Comm.

[10] Teng, X., Pham, H. and Jeske, D.R., 2006. Reliability Modeling of Hardware and Software Interactions and its Applications, IEEE Transactions Reliability, Vol.55, pp.571-577.

[11] Trivedi, K. S., Vasireddy, R., Trindade, D., Nathan,S., and Rick Castro., 2006. Modeling High Availability Systems. Proceeding Pacific Rim Dependability Conference PRDC.

[12] Trivedi, K.S., 2011. Probability and Statistics with Reliability, Queuing and Computer Science Applications, KPH Publishing.

[13] Welke, S.R., Johnson, B.W. and Aylor, J.H., 1995. Reliability Modeling of Hardware/Software Systems, IEEE Trans. Reliability, Vol.44, pp.413-418. 


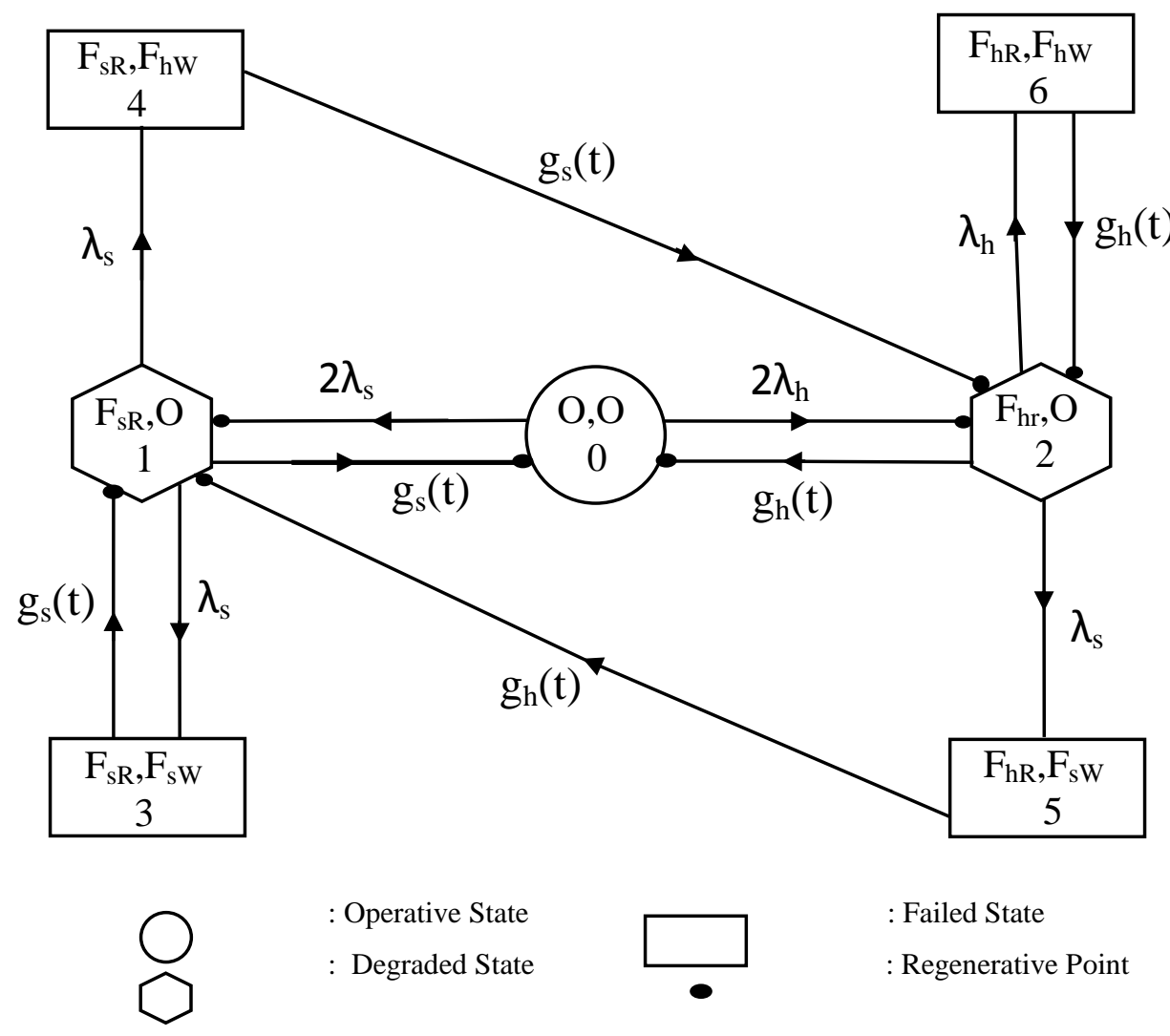

Fig. 1: State Transition Diagram

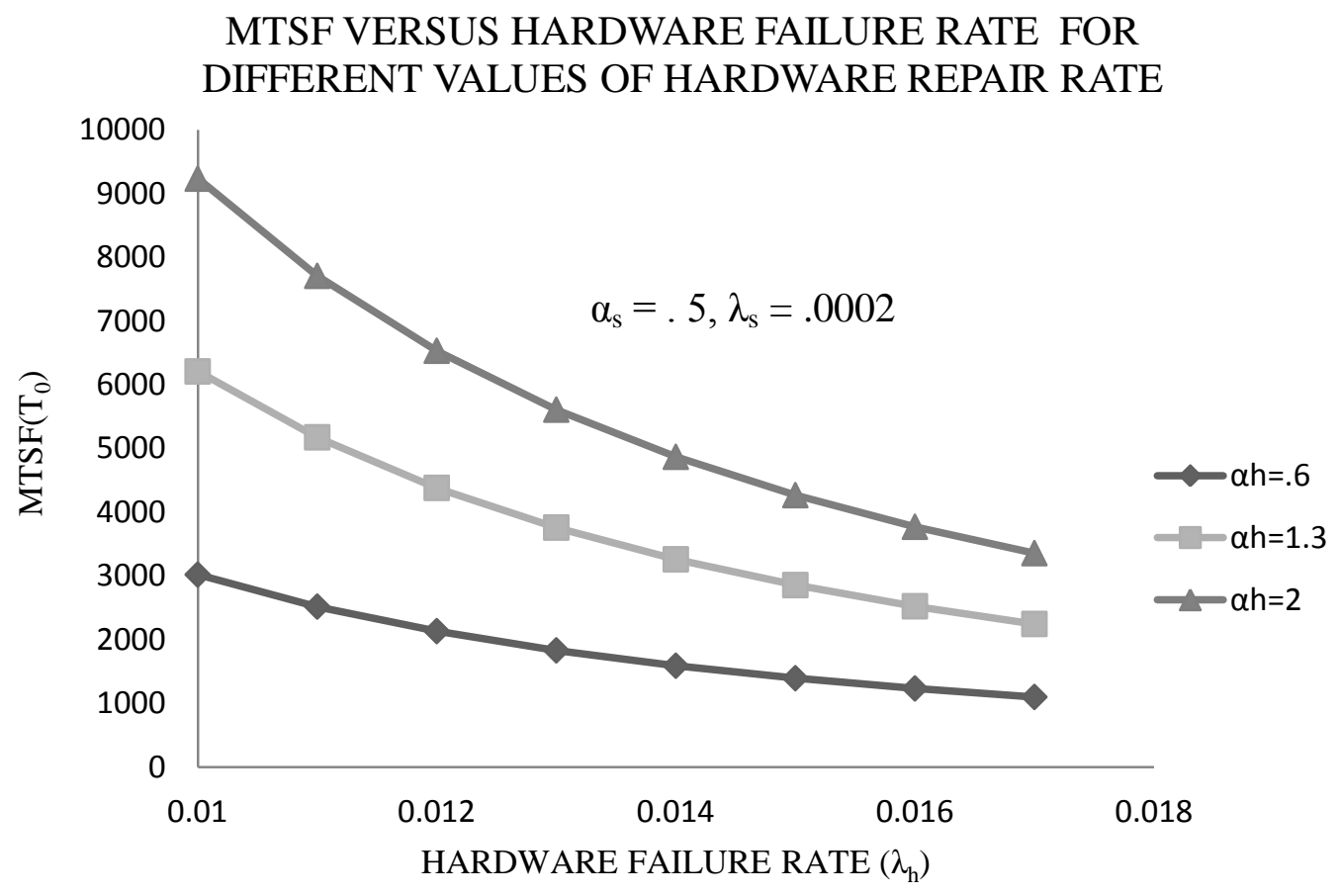

Fig. 2: MTSF versus Hardware Failure Rate 
MTSF VERSUS SOFTWARE FAILURE RATE FOR DIFFERENT VALUES OF SOFTWARE REPAIR RATE

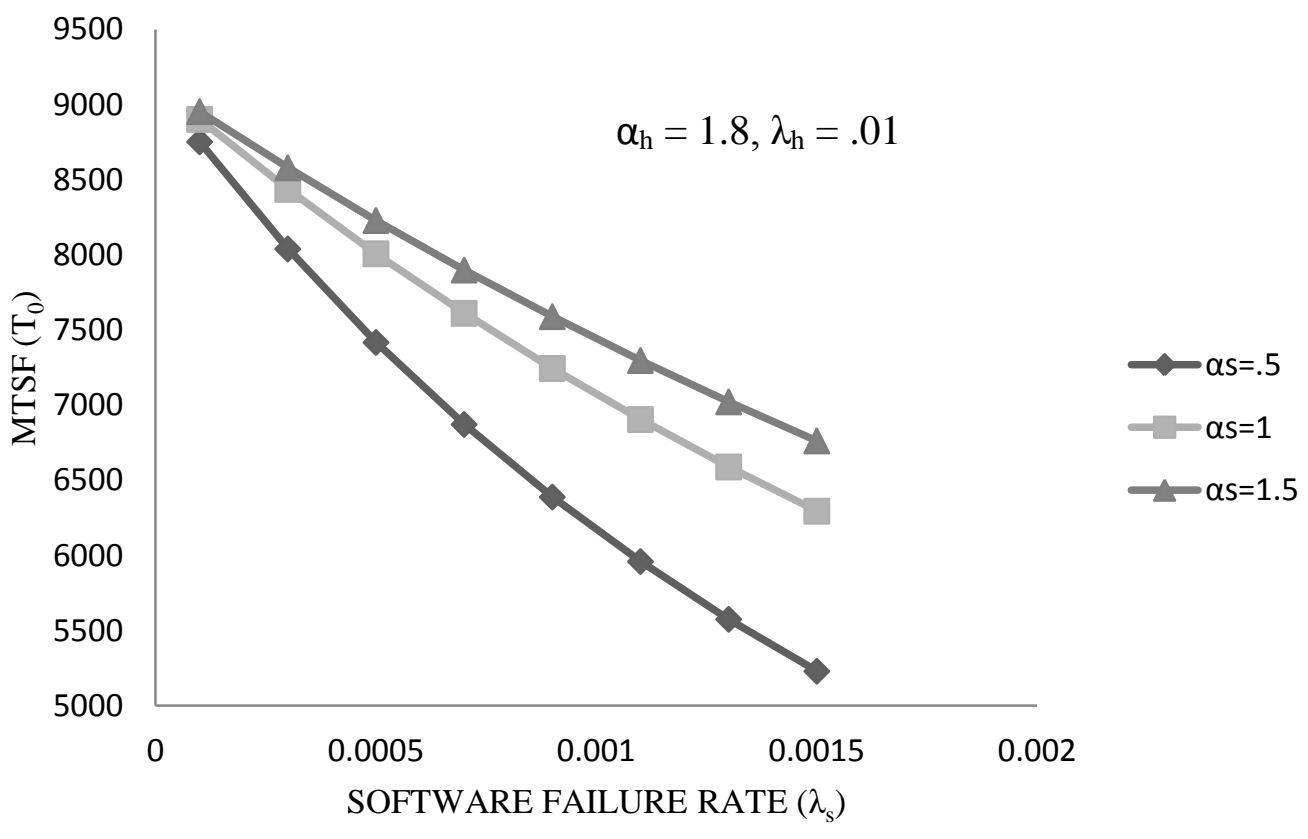

Fig. 3: MTSF Versus Software Failure Rate

MEAN UP TIME VERSUS HARDWARE FAILURE RATE FOR DIFFERENT VALUES OF HARDWARE REPAIR RATE

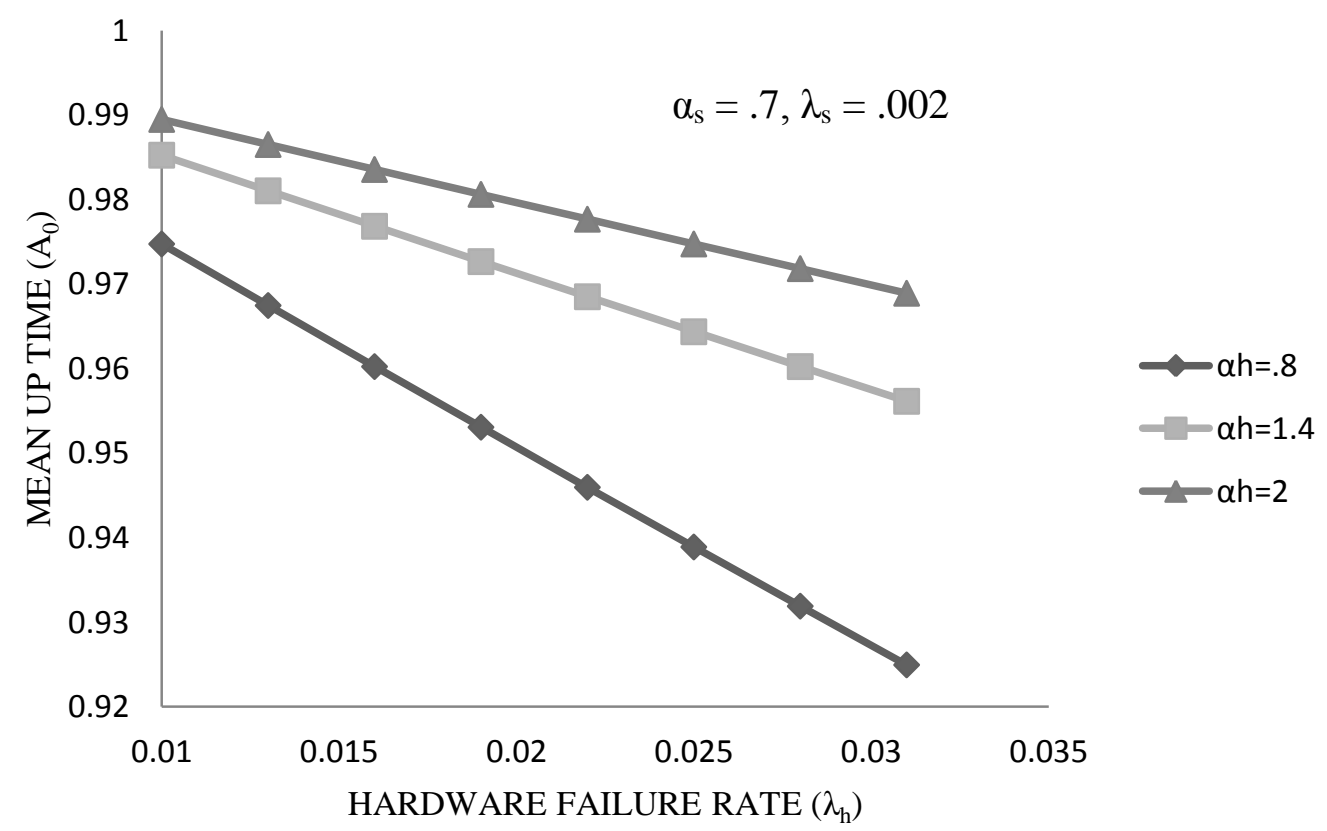

Fig. 4: Mean Up Time Versus Hardware Failure Rate 
MEAN UP TIME VERSUS SOFTWARE FAILURE RATE

FOR DIFFERENT VALUES OF SOFTWARE REPAIR RATE

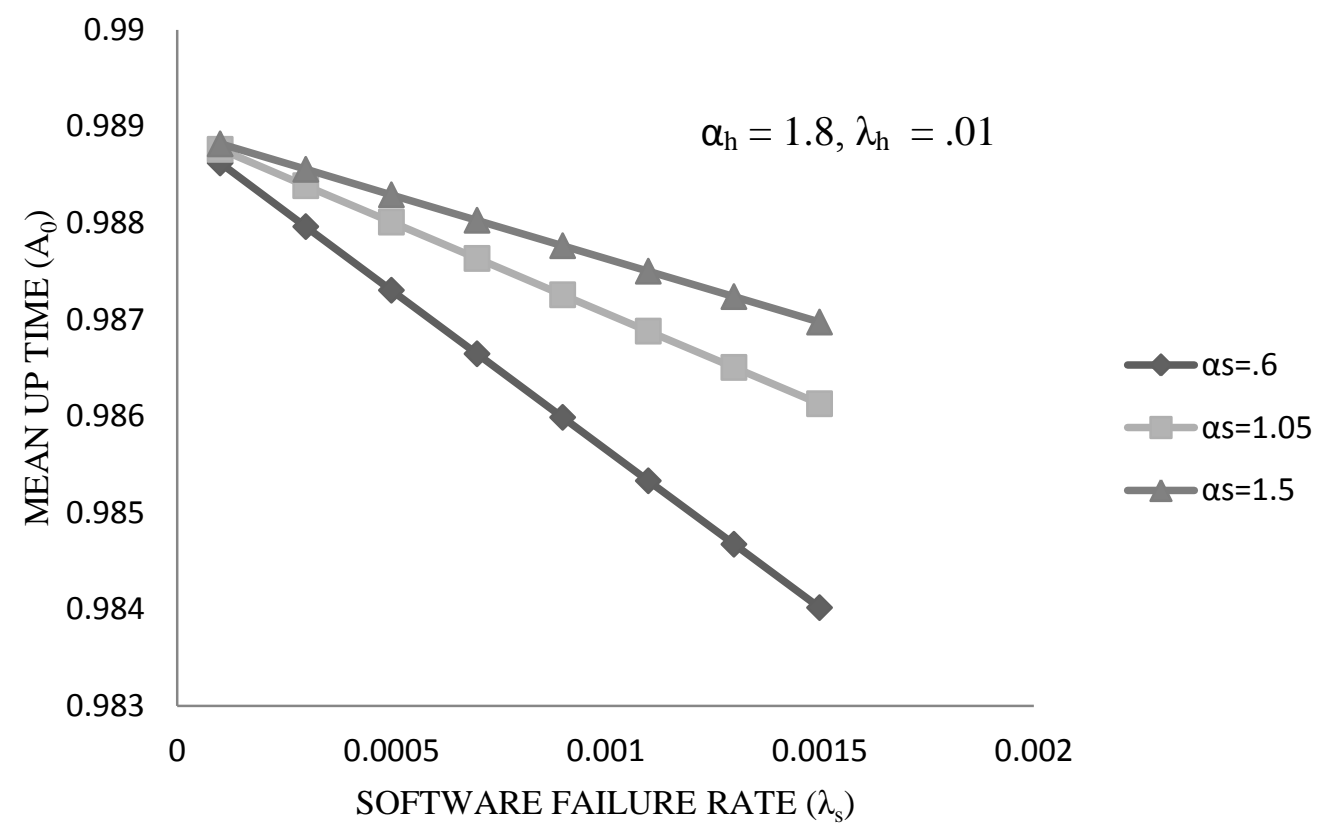

Fig. 5: Mean Up Time Versus Software Failure Rate

PROFIT VERSUS HARDWARE FAILURE RATE FOR DIFFERENT VALUES OF HARDWARE REPAIR RATE

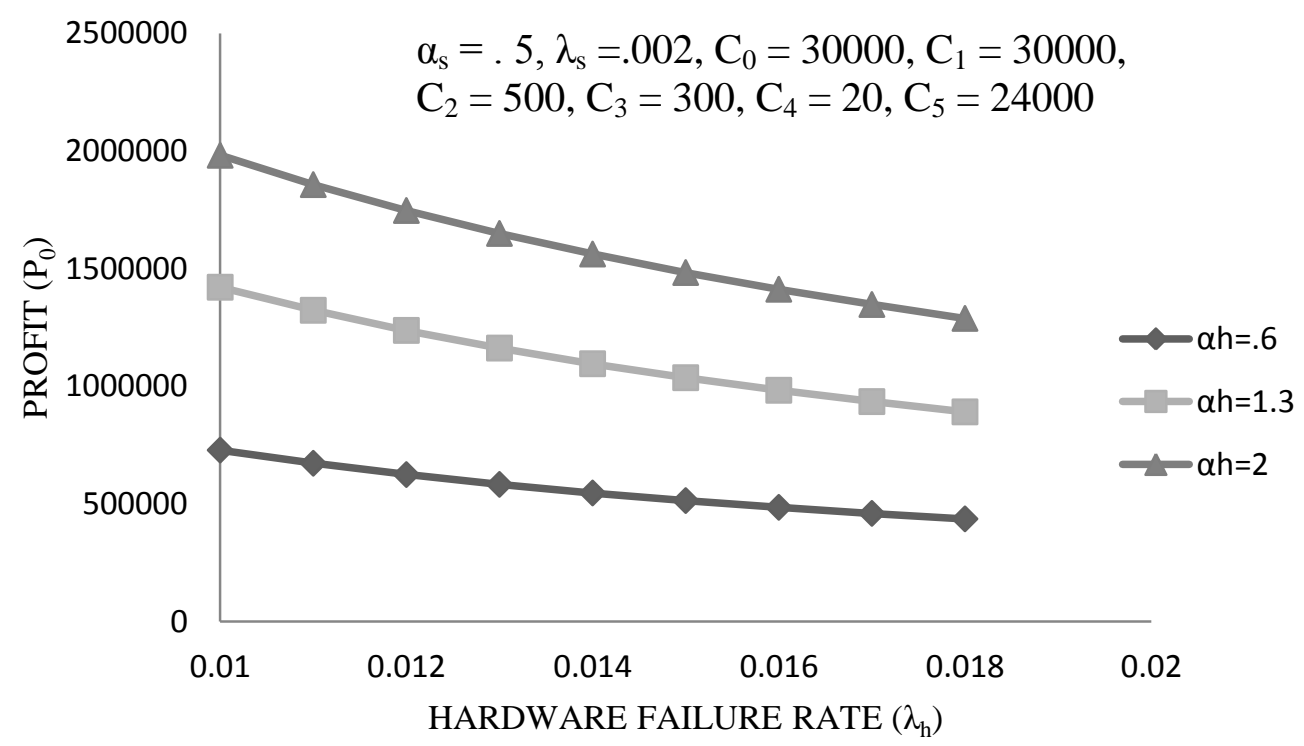

Fig. 6: Profit Versus Hardware Faifure Rate 
PROFIT VERSUS SOFTWARE FAILURE RATE FOR DIFFERENT VALUES OF SOFTWARE REPAIR RATE

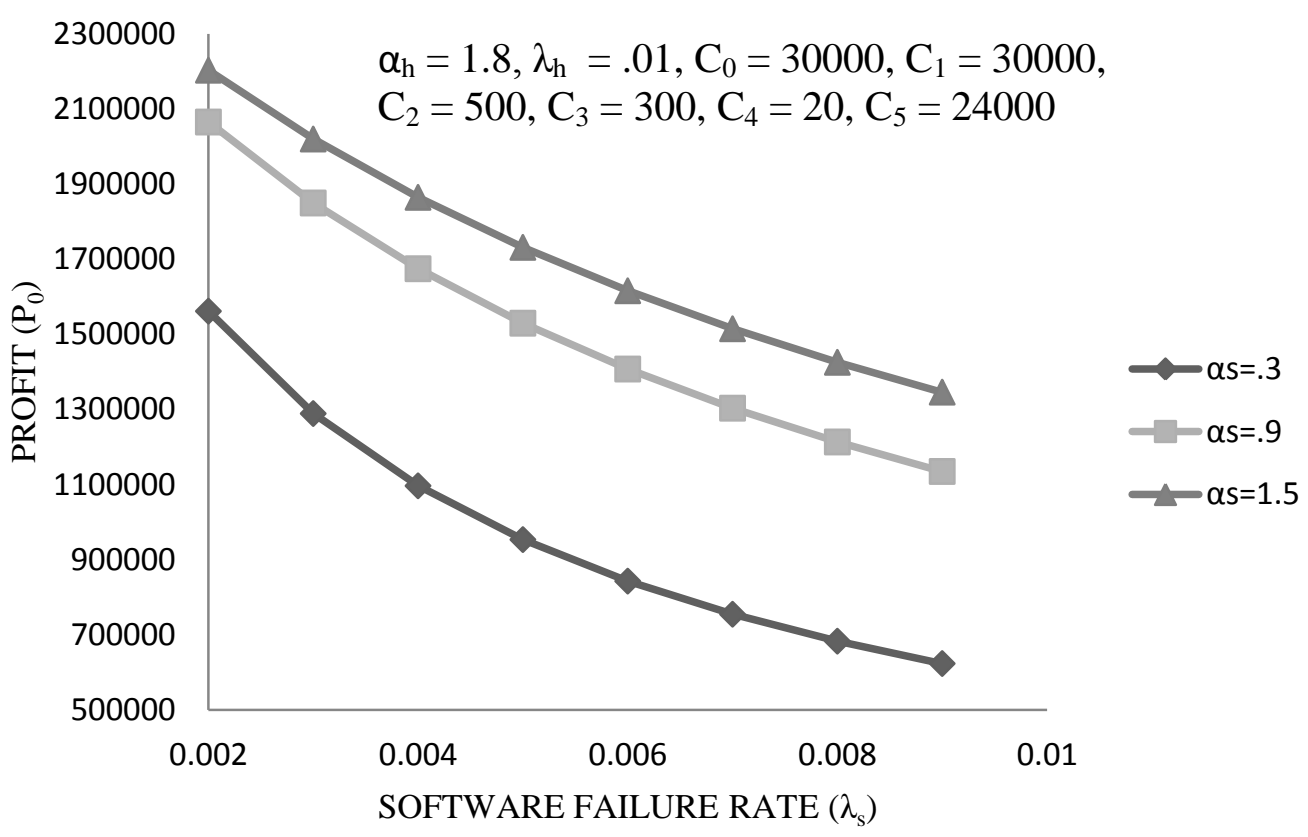

Fig. 7: Profit Versus Software Failure Rate 